\title{
Digitalization of Demonstration Method of Teaching and Effective Vocational Skills Delivery in Ghana Tertiary Institutions
}

\author{
Johnson Kofi Kassah $(\mathrm{PhD})^{1^{*}} \quad$ Agbeyewornu Kofi Kemevor $(\mathrm{PhD})^{2} \quad$ Brain Aheto-Domi ${ }^{3}$ \\ 1. Department of Vocational Education, St. Francis College of Education, P.O. Box 100, Hohoe, Volta Region, \\ Ghana \\ 2. Department of Graphic Design, University of Education-Winneba, P.O. Box 25, Winneba, Ghana \\ 3. Department of Vocational Education, Peki College of Education, P.O. Box 14, Peki Volta Region, Ghana
}

\begin{abstract}
The purpose of this study was to investigate the difficulties tutors face when using the traditional demonstration method of teaching for vocational skills delivery especially in large class sizes. The study also aimed to modernise the demonstration method for effective vocational skills delivery in Ghana tertiary institutions. The study employed Solomon four quasi-experimental research design. The study targeted tutors and students offering textiles related (fabric and leather decoration) component of vocational skills programme in Ghana Colleges of Education. Purposive and simple random sampling techniques were used. The sample size for the study was 322 ( 320 students \& tutors). The instruments used for data collection were interview guide, observation and skills achievement tests. The study revealed that tutors faced a lot of difficulties when using the traditional demonstration method of teaching for skills delivery in large vocational skills classes. The study also found that the students in experimental groups that were taught using the digital demonstration approach had higher scores on the skills achievement test conducted than those in the control groups that were taught using the traditional demonstration method of teaching. The study recommended that tutors should use digital demonstration method of teaching when vocational skills class size is large. Devices for effective use of the digital demonstration method should be provided to reduce the difficulties tutors faced when using the traditional demonstration method for skills delivery in large class sizes.
\end{abstract}

Keywords: Traditional demonstration method of teaching, digital demonstration method of teaching, effective, large class sizes.

DOI: $10.7176 / \mathrm{ADS} / 84-05$

Publication date:August $31^{\text {st }} 2020$

\section{Introduction}

The ambition of successive governments and educational stakeholders to increase enrolment through free and affordable education has resulted in negative students'-teacher ratio across the globe. Many formal education classrooms and lecture theatres have witnessed large class sizes over the years making it difficult to achieve quality skills delivery. Ghana as a developing nation is no exception and has its own fair share of large class sizes at the pre-tertiary and tertiary levels of education. Large class size occurs when the population of a class exceeds the approved number of pupils or students a teacher is supposed to teach at a time in educational system. Large classes or overcrowded classrooms are those where the students or pupils-teacher ratio exceeds the recommendation of the educational policy of a given country.

According to Ayeni and Olowe (2016), large classes' have negative implications on effective teaching in tertiary institutions because it frustrates the tutors or lecturers effective knowledge and skills delivering and assessments. Commeyras (2000) stated that effective teaching seems unviable for a teacher having large class sizes of 50,75, 100 or more. According to Oyebola (2017), effective demonstration of the teacher cannot take place in a large class size situation, because there is a limit to the number of learners or pupils a teacher can effectively manage well.

According to Murungi (2017), demonstration in a large class size affects pupils' test scores in the short run as well as their long-run human capital formation. When class size is small, the atmosphere for demonstration is better and pupils can receive more individualized attention than in large class size. Khan and Iqbal (2012) asserted that effective demonstration teaching is not possible in overcrowded classes because the majority of the teachers face discipline, physical and evaluation problems when handling large classes. Asodike and Onyeike (2015) opined that demonstration in large classes take a toll on the teacher's ability to manage time, requiring more time to be devoted to instruction, and behaviour management, thus leaving less time for actual instruction.

According to Yusuf et al. (2016), students' active participation is a major setback when a teacher is demonstrating skills to learners in a large class size. Olatunde (2010) stated that demonstration in large class size does not motivate students to attend or being present in classes because most of them especially the ones far away from the teacher may feel boring since they may not observe the process the teacher is demonstrating.

According to Yelkpieri et al. (2012), one of the causes of large class sizes worldwide is the staffing situation in the public tertiary institutions which has forced management to resort to large class size in order to 
make use of the limited staff available. Undeniably, large class sizes has become a big challenge to management of tertiary institutions in Ghana as well since staff-student ratio has become more difficult to manage. Digitalization of demonstration method teaching for effective vocational skills delivery in large class sizes in Ghana tertiary institutions could help curtail difficulties lecturers and tutors encounter when demonstrating skills in large class sizes.

\subsection{Statement of the Problem}

One of the best approaches of teaching practical skills is demonstration method of teaching. Demonstration method of teaching refers to teaching approach in which a teacher or lecturer show how something or a process is done to enable learners do the same thing on their own. In traditional demonstration method of teaching, a teacher show whatever the students are expected to do at the end of the lesson manually. The teacher or lecturer comes face-to-face by showing the learners how to do something and explaining the step-by-step process to them. There have been spiteful comments that utilizing traditional demonstration method to teach practical skills is becoming difficult due to large class sizes in Ghana tertiary institutions. In spite of the difficulties large class sizes post to traditional demonstration method of teaching skills, much has not been done to modernize the use method to effectively deliver vocational skills in large class sizes in Ghana Colleges of Education. This study was to help modernise the traditional demonstration method to help textiles related vocational skills subject tutors to overcome the difficulties they face when using demonstration method in large class sizes.

\subsection{Objectives}

i. To identify the difficulties tutors face when using traditional demonstration method of teaching in large vocational skills classes.

ii. To establish the ICT devices needed for effective use of digital demonstration method of teaching and their availability in the Colleges.

iii. To compare the scores of students taught using the traditional demonstration method and those taught using the digital demonstration method in large vocational skills classes.

\subsection{Hypothesis}

$\mathrm{H}_{\mathrm{O}} 1$ : There is no statistically significant relationship between practical skill achievements of students taught using traditional demonstration method and those taught using the digital demonstration method in large vocational skills classes.

\section{Methodology}

2.1 Research design

In this study, quasi- experimental design particularly Solomon Four-Group was used. This design was appropriate for this study because it helped the researchers to juxtapose the effective skills acquisition of the large class sizes taught using the traditional and digital demonstration methods of teaching in Colleges of Education in Ghana. According to White and Sabarwal (2014), quasi-experimental design involves the formation of a comparison group which are most frequently used when it is not possible to randomize participants or treatment groups and control groups. Quasi-experimental design is a research approach use to observe whether there is a causative relationship between dependent and independent variables (Rogers \& Revesz, 2013). In quasi-experimental, a pre-test and post-test are normally administered to both control and experimental groups, but only the experimental group receives treatment (Dogo, 2016). Quasi-experimental design is a combination of the pretest-posttest control group design and the posttest only design (McGahee, \& Tingen, 2014).

\subsection{Target Population}

The study targeted tutors and students offering textiles related (fabric and leather decoration) component of vocational education programme in Ghana Colleges of Education. The total population for the study was 322 (2 tutors \& 320 students).

\subsection{Sampling Techniques}

Simple random, proportional and purposive sampling techniques were employed in this study. Simple random sampling was used to assign the participants into the Solomon four-group ( 2 experimental groups \& 2 control groups) used for the study. The proportional sampling was used to form the control groups and experimental groups for the study. The purposive sampling was employed to select only tutors teaching textiles related vocational skills programme (fabric and leather decoration).

\subsection{Sample Size}

By using the Solomon four group, two control groups and two experimental groups were formed. Eighty (80) 
participants were assigned to each of the control and experimental groups. Table 1 shows the breakdown of the groups.

Table 1: Target population

\begin{tabular}{lc}
\hline Groups & Sample size \\
\hline Control Group 1 & 80 \\
Control Group 2 & 80 \\
Experimental Group 1 & 80 \\
Experimental Group 2 & 80 \\
Tutors & 2 \\
\hline Total & $\mathbf{3 2 2}$ \\
\hline
\end{tabular}

\subsection{Instrumentation}

This study utilised interview guide, observation and skills achievement tests to amass quantitative and qualitative data from the participants. The tutors who taught the lessons and five students from each of the experimental groups were also interviewed after the lessons to ascertain their skills achievements after they were exposed to the traditional and digital demonstration methods of teaching. Fabric and Leather Decoration lessons were observed to identify the challenges tutors faced when using the traditional demonstration method in large class sizes. The skills achievement tests were used to collect data on the students' skills acquisition in both experimental and control groups on the topics treated after students in the experimental groups received treatment.

\subsection{Data Collection Technique}

In this study, data collections started by interviewing Fabric and Leather Decoration tutors and students on the difficulties they face when traditional demonstration method is used to delivery practical skills topics. Being convinced that the use of traditional demonstration method post a lot of difficulties for both tutors and students, the researchers chose two practical topics (batik making \& manual screen printing) to be taught. The researchers created two control groups ( 80 students each) and two experimental groups ( 80 students each). Two tutors were involved in teaching the control and experimental groups. One tutor taught students in the Control Group 1 (CG1) and Experimental Group 1 (EG1) Batik Making Process using the traditional demonstration method while the second tutor taught manual screen printing process in control group 2 (CG2) and experimental group 2 (EG2) using the same traditional demonstration method. This was done to control tutor variability.

After teaching the control and experimental groups using the traditional demonstration method, only the students in the EG1 and EG2 were taught using the digital demonstration method. To employ digital demonstration method, each tutor used digital camera to record separately the sub topics of the topics (batik making \& manual screen printing) treated with the students in the control and experimental groups at preintervention stage. During the lessons, the recorded videos were shown to the learners in the experimental groups with the help of projector and laptop. As the students were watching the videos and repeating the processes on their own, the tutors were going round to attend to students who had issues with the understanding of portion of the processes in the videos. The videos were shown severally during the lessons to enable students who missed a step to observe the process again. The videos were also given out to the students in the EG1 and EG2 after each lesson for revision purposes and future use.

After exposing the students in EG1 and EG2 using the digital demonstration method, the researchers conducted sit down practical tests with the students in both the experimental groups and control groups one week after. The students in EG1 and CG1 were tested practically on batik making while those in EG2 and CG2 had test on manual screen printing process. The researchers marked the practical works of the students and recorded the marks. Tutors who taught the lessons and five students from each of the experimental groups were also interviewed by the researchers to ascertain their level of skills achievements after they were taught using both the traditional and digital demonstration methods.

\subsection{Data Analysis}

Both descriptive and inferential analyses were done. Descriptive statistics such as percentages and inferential statistics such as one-way ANOVA were carried out. The quantitative data such as skills achievement test scores of the control and experimental groups were analysed using SPSS. Descriptive statistics was used to compare the percentages of the control groups and experimental groups. The one-way ANOVA was used because the independent variables of this study had more than two levels. The null hypothesis formulated for the study was rejected at the $p$-value of 0.05 . 


\section{Results and Discussions}

\subsection{Results}

After teaching the experimental groups using the digital demonstration method, the researchers conducted skills achievement tests with the students in both control and experimental groups to find out their performance. Table 2 compares the frequencies and percentages of the skills achievement tests conducted with the students.

Table 2: Results of the test conducted after teaching students in experimental group 1 batik making using the digital demonstration method

\begin{tabular}{lccccc}
\hline Topic Taught & Grading & Frequency & Percentages & Frequency & Percentages \\
\hline & & CG1 & CG1 & EG1 & EG1 \\
Batik Making & $80-100$ & 17 & 21.3 & 74 & 92.5 \\
& $70-79$ & 8 & 10.0 & 6 & 7.5 \\
& $60-69$ & 2 & 2.5 & & \\
& $50-59$ & 16 & 20.0 & & \\
& $49 \&$ below & 37 & 46.2 & & \\
\hline
\end{tabular}

CG1 = Control Group 1; EG1 = Experimental Group 1

The results in Table 2 indicate the scores of students in the CG1 and EG1 when they were taught Batik Making using after students in the EG1 received treating by teaching them using digital demonstration method. The results indicated that majority $(\mathrm{n}=37,46.2 \%)$ of the students in the control group 1 scored marks between 0 49 while $(n=17,21.3 \%)$ scored between $80-100$. Also, $(n=16,20.0 \%)$ had marks between $50-59$ and $(n=8,10.0 \%)$ scored marks between 70-79. Finally, $(n=2,2.5 \%)$ in the control group 1 got marks between 60-69. It was found that students who had higher marks were closer to the tutor during the traditional demonstration and so were able to clearly viewed the process the tutor demonstrated while those who performed poorly were far from the tutor and so could not view the process clearly to enable them repeat the process on their own.

It can also be seen in Table 2 that $(n=74,92.5 \%)$ of the student in the EG1 who were taught using the digital demonstration method of teaching had marks between $80-100$ whilst $(n=6,7.5 \%)$ scored marks between $70-79$. This clearly showed that digital demonstration method of teaching was able to help tutors to effectively equipped students practical skills in large creative arts classes.

Table 3 compares the frequencies and percentages of the skills achievement tests conducted with the students in CG2 and EG2 after treatment was given to students in EG 2 by teaching them Manual Screen Printing Process using digital demonstration method.

Table 3: Results of the test conducted after teaching students in experimental group 2 manual screen printing using the digital demonstration method

\begin{tabular}{llcccc}
\hline Topic Taught & Grading & Frequency & Percentages & Frequency & Percentages \\
\hline Manual Screen Printing & & CG2 & CG2 & EG2 & EG2 \\
& $80-100$ & 14 & 17.5 & 71 & 88.8 \\
& $70-79$ & 10 & 12.5 & 8 & 10.0 \\
& $60-69$ & 18 & 22.5 & & 1.2 \\
& $50-59$ & 30 & 37.5 & & \\
\hline
\end{tabular}

CG2= Control Group 2 \& EG2= Experimental Group 2

The results Table 3 showed that majority of the students $(n=30,37.5 \%)$ in the control group 2 had marks between 50-59 whilst $(n=18,22.5 \%)$ scored between $60-69$. Furthermore, $(n=14,17.5 \%)$ had marks between 80 100 and $(n=10,12.5 \%)$ scored between $70-79$. Lastly, the least number of the students $(n=8,10 \%)$ in the control group 2 had marks between 0-49. The results of the students in the CG2 even though better than CG1 because the tutor grouped the students and did repeated demonstration in each group which made his work very tedious, some students still fell below $50 \%$.

Table 3 again $(n=71,88.8 \%)$ of the student in the EG2 who were taught using the digital demonstration method of teaching had marks between $80-100$, while $(n=8,10 \%)$ had marks between $70-79$. One student $(n=1.1 .2 \%)$. Had mark between 60-69. This again evidently indicated that digital demonstration method of teaching can make students skills acquisition when employed in large creative arts classes.

Ho1: There is no statistically significant relationship between practical skill achievements of students taught using traditional demonstration method and those taught using the digital demonstration method in large vocational skills classes.

The null hypothesis $\mathrm{H}_{\mathrm{O}} 1$ relating to the relationship between practical skills achievements of students taught using traditional demonstration method in large vocational skills classes and those taught using the digital demonstration method was tested using a one-way ANOVA. The null hypothesis was tested at 0.05 level of significance. Table 4 shows the results. 
Table 4 One-way ANOVA results on students taught using traditional method and digital demonstration method in large creative arts class

\begin{tabular}{lccccc}
\hline Group & $\begin{array}{c}\text { Sum of } \\
\text { Squares }\end{array}$ & df & $\begin{array}{c}\text { Mean } \\
\text { Square }\end{array}$ & F & Sig. \\
\hline Between Groups & 22.002 & 2 & 11.001 & 7.241 & .001 \\
Within Groups & 116.986 & 77 & 1.519 & & \\
\hline Total & $\mathbf{1 3 8 . 9 8 8}$ & $\mathbf{7 9}$ & & & \\
\hline
\end{tabular}

Table 4 illustrates the one-way ANOVA results which established the relationship between students taught using traditional and the digital demonstration methods in large vocational skills classes. The results showed that there was statistically significant relationship between the groups, $\mathrm{df}(77)=11.001 p=.01, \alpha=.05$ where $p<0.05$. Therefore, the null hypothesis $\mathrm{H}_{\mathrm{O}} 1$ that stated there is no statistically significant relationship between practical skill achievements of students taught using traditional demonstration method and those taught using the digital demonstration method in large vocational skills classes was rejected. The study, therefore, concluded that there was statistically significant relationship between students taught using traditional demonstration method in large vocational skills classes and those taught using the digital demonstration method.

\subsection{Discussions}

Objective One: To identify the difficulties tutors face when using traditional demonstration method of teaching in large vocational skills classes.

The lessons observed in large during data collection revealed that using traditional demonstration method of teaching in large vocational skills classes post a lot of challenges. During the lessons observed, the tutors who taught the lessons grouped the students and repeated demonstration was done in each group to enable students view the processes. This made tutors' work very tedious to the extent that quality assessment which was supposed to be carried out to ascertain students' progress in skills achievements suffered. Getting enough materials to demonstrate when students were grouped due to the large class sizes was another challenge. It was again found that tutors were not able to attend to individual student the traditional demonstration method was used. This is because by the time demonstration was done in two or three groups, the tutor was already tired. Slow learners also suffered in using the traditional demonstration method to teach in large vocational skills classes since the tutor had limited time to attend to them. Stealing, misused or damaging the meagre resources available for the traditional demonstration lessons were other difficulties encountered faced since the tutor found it difficult to control the moment of the students in the large class sizes. It was observed that safety rules were not followed during the traditional demonstration lessons in large classes since the tutors found it difficult to control the behaviour of the students. It was also observed that some students were not able to carry out instructions since the tutor was not able to attend to them due to the large class size.

Objective Two: To establish the ICT devices needed for effective use of digital demonstration method of teaching and their availability in the Colleges.

For effective vocational skills delivery using the digital demonstration method of teaching, ICT devices such as smartboard, laptops, computers, tablets, projectors, sound speakers, smartphones and digital cameras are the electronic teaching and learning materials needed. Internet facilities are also needed to enable tutors easily share the digital lessons with students through Twitter, Instagram, Whatsapp, Telegram and any other social media platform for revision purposes and future use. They are also needed to enable students download the digital lessons tutors may share.

About the availability of electronic devices in the colleges, the study revealed that the vocational skills department had projectors and laptops procured by the Colleges but in some Colleges these devices got spoilt and they were not repaired or replaced. The study found that smartboards and other devices such as smartphones, digital cameras, and sound speakers were not available in vocational skills departments in the colleges.

Objective Three: To compare the scores of students taught using the traditional demonstration method and those taught using the digital demonstration method in large vocational skills classes.

The study revealed that the students in experimental groups that were taught using digital demonstration approach had higher grades in the skills achievement test conducted than those in the control groups that were taught using the traditional demonstration method. It was found that the video assisted nature of the digital demonstration approach and the giving out of the videos to the students for future use enable students in the experimental groups perform very well in the practical test conducted than their counterpart in the control groups that were not taught using the digital demonstration method of teaching. The results of the study indicated that digital demonstration method of teaching in large vocational skills classes did not only curtail the difficulties tutors face when demonstrating in large classes but also increase students understanding and quality skills achievements. The results of hypothesis formulated and tested also affirmed the qualitative data obtained through observation and interview conducted. The null hypothesis tested revealed there was statistically significant relationship between students taught using the digital demonstration method and those taught using the 
traditional demonstration method of skills delivery.

\section{Conclusion}

Based on the findings of the study, it is concluded that tutors of vocational skills faced a lot of difficulties when delivering skills in large class sizes. ICT devices which can aid the use of digital demonstration method of teaching were not available in the vocational skills departments in Colleges. The study also concluded that students in experimental groups who were taught using the digital demonstration method achieved skills and performed better than those in the control groups who were exposed to the traditional demonstration method of teaching. There was also statistically significant relationship between students taught using the digital demonstration approach and their counterparts taught using the traditional demonstration method.

\section{Recommendations}

The study made the following recommendations based on the findings and the conclusions:

i. tutors should be encouraged to use the digital demonstration method of teaching when equipping trainees with the vocational skills needed to perform in the job market.

ii. Devices needed for effective use of digital demonstration method should be provided by managements of the Colleges of Education.

\section{References}

Asiamah, N., Mensah, H. K., \& Oteng-Abayie, E. (2017). General, target, and accessible population: demystifying the concepts for effective sampling. The Qualitative Report, 22(6), 1607-1621. $\mathrm{http}: / /$ nsuworks.nova.edu/tqr/vol22/iss6/9

Asodike, J.D. \& Onyeike, V.C. (2015). Managing large classes in developing countries. Global Journal of Educational Research, 15, 31-39. file://C:/Users/franco/Downloads/132865-Article\%20Text-358417-1-1020160401.pdf

Babbie, E. (2010). The practice of social research. Belmont University.

Epri, M.L. (2016). A case study on the impact of large classes on student learning. Contemporary PNG Studies: DWU Research Journal, $24, \quad 95-109$. https://www.dwu.ac.pg/en/images/All_Attachements/Research\%20Journals/vol_24/2016-V24-8_Epri_M.pdf.

Khan, P. \& Iqbal, M. (2012). Overcrowded classrooms: A serious problem for teachers. Sarhad University of Science and Information Technology.

McGahee, T.W. \& Tingen, M.S (2014). The Use of the Solomon Four-Group Design in Nursing Research, Southern Online Journal of Nursing Research, $9 \quad$ (1), 1-8. https/pdfs.semanticscholar.org/6c72/c7b571a0ff41a7c78fa98b8c2b5b6f9614dd.pdf? $\mathrm{ga}=2.103159043 .2070318550 .1596721928-1912572333.1590258637$

Murungi, C.G. (2017). Class size and acquisition of reading skills amongst grade III pupils in Kenyenya SubCounty, Kenya. International Researchers, $6 \quad$ 32-43. https://irlibrary.ku.ac.ke/bitstream/handle/123456789/18719/Class\%20size.pdf?sequence=1\&isAllowed=y

Olaleye, F. O., Ajayi, A., Oyebola, O. B. \& Ajayi, O. A. (2017). Impact of overcrowded classroom on academic performance of students in selected public secondary schools in Surelere local government of Lagos state, Nigeria. International Journal of Higher Education and Research, 7(1), 110-132. file://C:/Users/franco/AppData/Local/Temp/22.ImpactofOvercrowded.pdf

Olatunde Y.P. (2010). Class size and students' mathematics achievement of senior secondary schools in South-

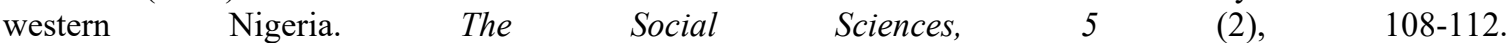
http://docsdrive.com/pdfs/medwelljournals/sscience/2010/108-112.pdf

Rogers, J. \& Revesz, A. (2020). Experimental and quasi-experimental designs. ResearchGate.

Taherdoost, H. (2016). Sampling Methods in Research Methodology: How to Choose a Sampling Technique for Research. International Journal of Academic Research in Management. 5 (2) 18-27. http://elvedit.com/journals/IJARM/wp-content/uploads/Sampling-Method-in-Research-

Methodology_-How-to-Choose-a-Sampling-Technique-for-Research.pdf

White, H., \& S. Sabarwal (2014). Quasi-experimental design and methods, methodological briefs: Impact evaluation 8. UNICEF Office of Research.

Yelkpieri, D., Namale, M., Esia-Donkoh, K. \& Ofosu-Dwamena, E. (2012). Effects of large class size on effective teaching and learning at the Winneba campus of the UEW (university of education, Winneba), Ghana. US- China Education Review, 319-332. file://C:/Users/franco/Downloads/Effects_of_Large_Class_Size_on_Effective.pdf

Yusuf, T.A., Onifade, C.A. \& Bello, O.S. (2016). Impact of class size on learning, behavioral and general attitudes of students in secondary schools in Abeokuta, Ogun State Nigeria. Journal of Research Initiatives, 2 (1), 1-16. file:///C:/Users/franco/Downloads/paperonclasssizepublished.pdf 